\title{
A comparative study of COPD burden between urban vs rural communities in northern Thailand
}

\author{
This article was published in the following Dove Press journal: \\ International Journal of COPD \\ 2 June 2015 \\ Number of times this article has been viewed
}

\section{Chaicharn Pothirat \\ Warawut Chaiwong \\ Nittaya Phetsuk \\ Sangnual Pisalthanapuna \\ Nonglak Chetsadaphan \\ Juthamas Inchai}

Division of Pulmonary, Critical Care and Allergy, Department of Internal

Medicine, Faculty of Medicine, Chiang

Mai University, Chiang Mai, Thailand

Correspondence: Chaicharn Pothirat Division of Pulmonary, Critical Care and Allergy, Department of Internal Medicine, Faculty of Medicine, Chiang Mai University, I I0 Inthavaroros Road, Sri Phum, Muang Chiang Mai District, Chiang Mai 50200, Thailand

Tel +6653946228

Fax +66 53895 II 7

Email cpothira@med.cmu.ac.th
Background: COPD prevalence and consequent burden are expected to rapidly increase worldwide. Until now, there has been no community-based study of COPD in Thailand.

Purpose: We aimed to compare the prevalence, clinical characteristics, disease severity, previous diagnosis, and management of COPD between urban and rural communities.

Materials and methods: A population-based cross-sectional study was designed to compare COPD prevalence and burden in rural and urban communities in Chiang Mai Province, Thailand. The COPD subjects were diagnosed and severity categories assigned using Global Initiative for Chronic Obstructive Lung Disease (GOLD) criteria. The prevalence between the groups was compared using risk regression analysis. Unpaired $t$-test and chi-square were used to compare differences between the groups.

Results: There were 574 and 293 enrolled subjects with acceptable spirometry, in rural and urban communities respectively. The prevalence of COPD in general and COPD in females was higher in the rural group (6.8\% vs $3.7 \%$ and $4.4 \%$ vs $0.9 \%$, respectively) across all independent variables. However, after adjustment for age, sex, and smoking status, no significant differences were demonstrated. Although the pulmonary function and disease severity between the two groups were not significantly different, the tendency was more pronounced in the rural group (COPD stage III-IV: $65.0 \%$ vs $33.3 \%$ ). Most of the COPD patients in both groups were underdiagnosed $(80.0 \%$ vs $77.2 \%)$ and undertreated $(85.0 \%$ vs $81.9 \%)$. None of the patients in the study had participated in exercise training programs.

Conclusion: The prevalence of COPD in general and particularly COPD in females tended to be higher, with more severe disease in the rural community. However, both groups were similarly underdiagnosed and undertreated.

Keywords: chronic obstructive pulmonary disease, spirometry, prevalence

\section{Introduction}

Since 2010, COPD has been the third leading cause of death. ${ }^{1}$ COPD is a progressive, destructive disease of the airways and lung parenchyma, with no clear pathological or clinical starting points. Its prevalence and consequent burden is expected to rise with rapidly increasing smoking rates in developing countries. ${ }^{2}$ Overall, the prevalence of COPD in the general population is estimated to be about $1 \%$ across all ages, rising steeply to $8 \%-10 \%$ or higher in individuals 40 years or older. ${ }^{3}$ The COPD prevalence, using an estimation model, varies twofold between 12 Asian countries, ranging from $3.5 \%$ to $6.7 \%$, with Thailand between the two extremes at $5.0 \% .{ }^{4}$ In northern Thailand, hospital-based COPD patients are mostly in advanced stages and are undertreated; 5 however, there are no community-based studies of COPD prevalence, disease severity, and management. The objectives of this study were to compare the prevalence, clinical characteristics, disease severity, previous physician diagnosis, and management of COPD between urban and rural communities in Chiang Mai Province, Thailand. 


\section{Materials and methods}

A cross-sectional population-based study was designed to compare COPD prevalence in adults over 40 years living in municipal areas of Chiang Mai (urban community) vs the Chiang Dao District (rural community), Chiang Mai Province, Thailand, between 2008 and 2010. The sample size was calculated using registered populations, with a total of 60,000 (urban) and 22,000 (rural) adults. A minimal sample size of 398 was determined using Slovin's formula ${ }^{6}$ with a 95\% confidence interval (CI) (accepted a type 1 error rate of $0.05)$. We anticipated that $60 \%$ of available subjects would be unable to participate or would decline participation, so we planned to enroll approximately 636 subjects (318 subjects for each community). Selection of the community areas in each group was performed by random-route methodology. The chosen areas were then divided into several blocks based on geographical area and numbers of street, and systematic sampling of households within these randomized blocks was conducted. Every third house within each block was selected, and only one patient was interviewed per household. Each patient participated in a face-to-face interview, using a previously validated respiratory health questionnaire adapted from the European Community Respiratory Health Survey (ECRHS), ${ }^{7}$ administered by a trained interviewer, for information on general health, chronic respiratory symptoms, and previous physician-diagnosed respiratory diseases. Three levels of economic status were assigned based on annual household income: low ( $\leq 70,000$ Baht), moderate (70,001-195,749 Baht), and high ( $\geq 195,750$ Baht). ${ }^{8}$ In addition, history of biomass fuel exposure, as hour-years, and occupation were also recorded for each participant. ${ }^{9}$ At the onset of the study, all subjects were invited to the administrative office at selected hospitals located in each community for a face-to-face interview (to confirm their information) and for a physical exam by a pulmonologist from the study team. Every enrolled subject received a chest radiograph, and post-bronchodilator (BD) spirometry using the same instrument (Spirobank ${ }^{\mathrm{TM}}$; Medical International Research S.r.l., Via del Maggiolino, Roma, Italy). Standard chest radiograph and the standard American Thoracic Society/European Respiratory Society post-BD spirometry ${ }^{10}$ results were further used for interpretation of study results, by a radiologist and pulmonologists, respectively, in the study team. The spirometric values, recorded as \% predicted, were calculated using National Health and Nutrition Examination Survey (NHANES) III reference equations. ${ }^{11}$ A correction factor of 0.88 was applied to the forced vital capacity (FVC) and forced expiratory volume in first second
$\left(\mathrm{FEV}_{1}\right)$ predicted, to correct for variations between European and Asian races. ${ }^{12}$ Subjects with current unstable psychiatric illness, alcoholic addiction, severe systemic comorbidity (homebound or hospitalized subjects), and an inability to perform spirometry were excluded from this study. All data, including age, sex, body mass index (BMI), smoking history, biomass fuel exposure, socioeconomic status, occupation, respiratory symptoms, previous medical history, and prior diagnosis of respiratory diseases, general physical examination, and chest radiographic findings interpreted by a radiologist, were evaluated.

The COPD subjects were diagnosed by detection of airflow obstruction, based on a fixed threshold criterion (a ratio of post-BD FEV $/ \mathrm{FVC}$ less than 0.7 ), ${ }^{13}$ and normal or abnormal chest radiographs compatible with the disease (the presence of diffuse pulmonary hyperinflation with flattened diaphragms). The COPD subjects were further interviewed by a pulmonologist in the study team for history of previous spirometry test, previous physician diagnosis, and treatment with inhaled long acting bronchodilators +/- inhaled corticosteroid and/or participation in an exercise training program within the past year.

This study was approved by the Ethics Committee of the Faculty of Medicine, Chiang Mai University.

\section{Statistical analysis}

Results for numerical values were expressed as mean $\pm \mathrm{SD}$, and those for categorical data were expressed as absolute frequencies and percentages. Unpaired $t$-test and chi-square were used to compare differences between the groups for numerical values and categorical data, respectively. Disease prevalence between the groups was compared using risk regression analysis to account for age, sex, and smoking status. Results were displayed as relative risk ratio with a 95\% CI. Statistical significance was set at $P<0.05$. All analyses were carried out with SPSS statistical package, version 16 for Windows.

\section{Results}

A total of 1,508 subjects ( 888 from urban areas and 620 from rural areas) were initially screened by face-to-face interview for this study, resulting in 1,003 who were expected to undergo further investigations at the hospitals. On the appointed dates, 631 and 372 subjects from the urban and rural groups made their appointments. The subjects with spirograms that met acceptability criteria (574 [urban] and 293 [rural]) were analyzed. The flow chart showing subject participation throughout the study is shown in Figure 1. The demographic data 


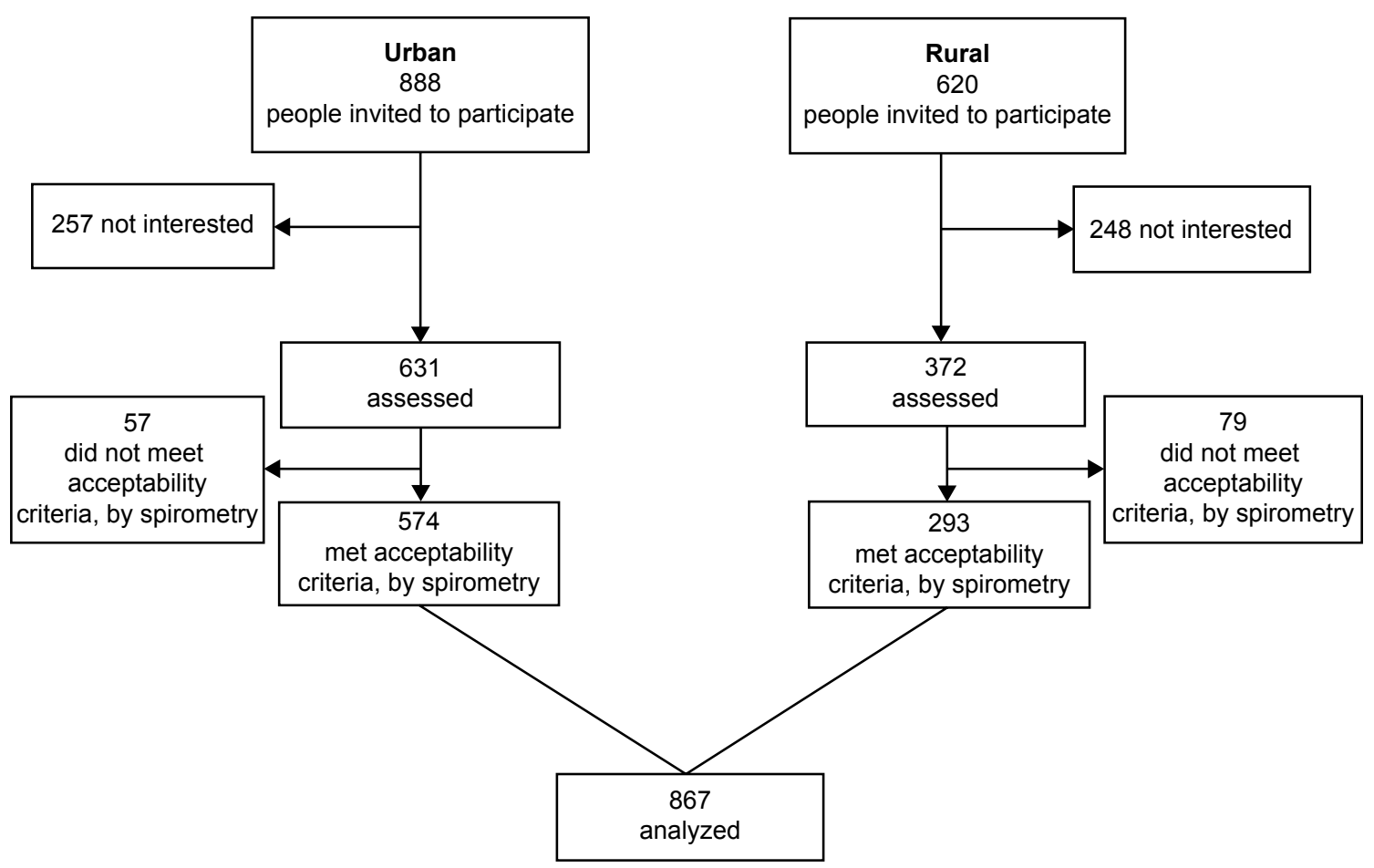

Figure I Flow chart showing subject participation throughout the study.

of the excluded subjects in each group was not significantly different from those of the analyzed subjects.

The demographic characteristics of the two community groups are shown in Table 1. There was no statistically significant difference in the mean age of subjects between the two groups (52.9 \pm 10.2 years vs $56.6 \pm 11.6$ years, respectively) $(P=0.065)$, but the rural group had more elderly subjects (age $>60$ years) $(P<0.001)$. There were significant differences between the groups in terms of education, occupation, and economic status $(P<0.001)$. The subjects in the rural group were significantly more underweight $\left(<18.5 \mathrm{~kg} / \mathrm{m}^{2}\right)$ than those in the urban group $(P<0.001)$. The rural group had significantly more smokers, current smokers, smoking packyears, duration of smoking, and percentage of smokers with smoking history $>5$ pack-years $(P<0.001)$. There was no significant difference between the groups in term of exposure to biomass fuel smoke $(P=0.649)$. The pulmonary function tests of the two groups in terms of $\mathrm{FVC}, \mathrm{FEV}_{1}$, and ratio of $\mathrm{FEV}_{1} / \mathrm{FVC}$ were not significantly different.

The prevalence of COPD between the two groups were significantly different by univariable risk regression analysis (Table 2), with the overall rate almost twofold higher in the rural group than in the urban group (6.8\% vs 3.7\%) $(P=0.038)$, and the prevalence in females was also significantly higher than in the urban group $(4.4 \%$ vs $0.9 \%)$ $(P=0.012)$. However, the prevalence of COPD and COPD in females became insignificant by multivariable risk regression analysis (adjusted risk ratio for age, sex, and smoking status). Prevalence of COPD in elderly subjects and in chronic smokers ( $>5$ pack-years) subjects were also not significantly different $(9.6 \%$ vs $13.4 \%$ [ $P=0.342]$ and $11.2 \%$ vs $10.8 \%$ $[P=0.913]$, respectively).

The characteristics of COPD patients between the two groups were not significantly different in terms of the means age of subjects, smoking status, smoking pack-years, chest radiograph findings, previous physician diagnosis, and treatment of COPD (Table 3). However, the COPD subjects in the rural group were significantly more underweight $(P=0.002)$ and had a longer duration of smoking $(P=0.015)$. There were significant differences between the groups in terms of education, occupation, and economic status $(P<0.05)$. There was no significant difference between the groups in term of exposure to biomass fuel smoke $(P=0.630)$. No COPD subjects from either of the two groups had ever performed spirometry. They were clinically diagnosed as COPD by their physicians. The pulmonary function test results $\left(\mathrm{FVC}, \mathrm{FEV}_{1}, \%\right.$ predicted $\mathrm{FVC}, \%$ predicted $\mathrm{FEV}_{1}$, and ratio of $\mathrm{FEV}_{1} / \mathrm{FVC}$ ) of COPD subjects in the rural group tended to be lower than those in the urban group, but the difference did not reach a statistically significant level. Most rural COPD subjects were clinically more severe by Global Initiative for Chronic Obstructive Lung Disease (GOLD) 
Table I Baseline characteristics of enrolled subjects in the urban and rural areas

\begin{tabular}{|c|c|c|c|}
\hline \multirow[t]{2}{*}{ Characteristics } & \multicolumn{2}{|c|}{ Total subjects $(n=867)$} & \multirow[t]{2}{*}{$P$-value } \\
\hline & Rural (n=293) & Urban $(n=574)$ & \\
\hline Male sex & $157(53.6)$ & $232(40.4)$ & $<0.001$ \\
\hline Age (years) & $56.6 \pm 11.6$ & $52.9 \pm 10.2$ & 0.065 \\
\hline Age $>60$ years & $112(38.2)$ & $135(23.5)$ & $<0.001$ \\
\hline Occupation & & & $<0.001$ \\
\hline Laborer & $122(4 \mid .6)$ & I7| (29.8) & \\
\hline Farmer & I0I (34.5) & $18(3.1)$ & \\
\hline Self-employed & $44(15.0)$ & $256(44.6)$ & \\
\hline Officer & $26(8.9)$ & $129(22.5)$ & \\
\hline Level of education & & & $<0.001$ \\
\hline Primary & $92(31.4)$ & $4 I(7.1)$ & \\
\hline Secondary & II 5 (39.2) & $27 \mid(47.2)$ & \\
\hline College & $52(17.8)$ & $167(29.1)$ & \\
\hline University & $34(11.6)$ & $95(16.6)$ & \\
\hline Level of economic status (Baht/year) & & & $<0.001$ \\
\hline Low $(\leq 70,000)$ & I $37(46.8)$ & $218(38.0)$ & \\
\hline Moderate $(70,00 I-\mid 95,749)$ & $136(46.4)$ & $242(42.2)$ & \\
\hline High $(>195,749)$ & $20(6.8)$ & $114(19.9)$ & \\
\hline BMI $\left(\mathrm{kg} / \mathrm{m}^{2}\right)$ & $19.8 \pm 3.9$ & $24.3 \pm 3.8$ & $<0.001$ \\
\hline BMI classification & & & $<0.001$ \\
\hline$<18.5 \mathrm{~kg} / \mathrm{m}^{2}$ & $176(60.1)$ & $82(14.3)$ & \\
\hline $18.5-22.9 \mathrm{~kg} / \mathrm{m}^{2}$ & $103(35.2)$ & $328(57.1)$ & \\
\hline $23.0-24.9 \mathrm{~kg} / \mathrm{m}^{2}$ & $14(4.7)$ & $137(23.9)$ & \\
\hline $25.0-29.9 \mathrm{~kg} / \mathrm{m}^{2}$ & $0(0.0)$ & $27(4.7)$ & \\
\hline Smoking status & & & $<0.001$ \\
\hline Nonsmoker & $108(36.9)$ & $359(62.5)$ & \\
\hline Smoker & $185(63.1)$ & $215(37.5)$ & \\
\hline Current smoker & $115(62.2)$ & $93(43.3)$ & \\
\hline Ex-smoker & $70(37.8)$ & $122(56.7)$ & \\
\hline Smoking (pack-years) & $31.5 \pm 25.6$ & $16.4 \pm 10.2$ & $<0.001$ \\
\hline Smoking $>5$ pack-years & $185(63.1)$ & $152(26.5)$ & $<0.001$ \\
\hline Duration of smoking (years) & $37.8 \pm 14.2$ & $24.3 \pm 13.0$ & $<0.001$ \\
\hline Biomass fuel smoke status & & & 0.206 \\
\hline No exposure & $282(96.2)$ & $56 \mathrm{I}(97.7)$ & \\
\hline Exposure & II (3.8) & $13(2.3)$ & \\
\hline$<100$ hour-years & $9(81.8)$ & $12(92.3)$ & 0.439 \\
\hline $100-200$ hour-years & $2(18.2)$ & I (7.7) & \\
\hline$>200$ hour-years & $0(0.0)$ & $0(0.0)$ & \\
\hline Duration of exposure (hour-years) & $41.0 \pm 12.4$ & $31.7 \pm 8.8$ & 0.649 \\
\hline \multicolumn{4}{|l|}{ Spirometric results } \\
\hline FVC (L) & $2.94 \pm 0.93$ & $2.83 \pm 0.83$ & 0.647 \\
\hline$\%$ predicted FVC & $87.9 \pm 11.3$ & $86.06 \pm 14.74$ & 0.367 \\
\hline $\mathrm{FEV}_{1}(\mathrm{~L})$ & $2.30 \pm 0.40$ & $2.22 \pm 0.63$ & $0.24 I$ \\
\hline$\%$ predicted $\mathrm{FEV}$, & $86.4 \pm 16.7$ & $85.50 \pm 15.38$ & 0.660 \\
\hline $\mathrm{FEV}_{\mathrm{I}} / \mathrm{FVC}(\%)$ & $81.9 \pm 8.42$ & $82.2 \pm 6.44$ & 0.581 \\
\hline
\end{tabular}

Note: Data are expressed as $\mathrm{n}(\%)$ or mean $\pm \mathrm{SD}$.

Abbreviations: BMI, body mass index; $\mathrm{FEV}_{1}$, forced expiratory volume in first second; FVC, forced vital capacity; SD, standard deviation.

classification than those in the urban group (GOLD III-IV: $65.0 \%$ vs $33.3 \%$ ); however there was no statistically significant difference $(P=0.146)$. Large percentages of COPD subjects from both groups had never been diagnosed $(80.0 \%$ [rural] vs 76.2\% [urban]) or treated for COPD by physicians ( $85.0 \%$ [rural] vs $80.9 \%$ [urban]). The minority previously diagnosed were diagnosed by their physicians without spirometry. Moreover, none in either group had participated in an exercise training program.

\section{Discussion}

This is the first community-based epidemiological study of COPD burden comparing urban and rural communities in Thailand. The prevalence of COPD is difficult to evaluate 
Table 2 Prevalence of COPD between the rural and urban communities, by sex, age group, and smoking pack-years, by univariable and multivariable risk regression analysis

\begin{tabular}{|c|c|c|c|c|c|c|}
\hline Characteristics & Rural & Urban & $\begin{array}{l}\text { Relative risk } \\
(95 \% \mathrm{Cl})\end{array}$ & $P$-value & $\begin{array}{l}\text { Adjusted relative } \\
\text { risk }(95 \% \mathrm{Cl})\end{array}$ & $P$-value \\
\hline Total & $20 / 293(6.8)$ & $2 \mathrm{I} / 574(3.7)$ & $1.9(1.0-3.6)$ & $0.038^{*}$ & $1.0(0.7-1.3)$ & 0.765 \\
\hline Female sex & $6 / 136(4.4)$ & $3 / 342(0.9)$ & $5.2(1.3-21.2)$ & $0.012^{*}$ & $1.0(0.2-4.7)$ & 0.937 \\
\hline Age $>60$ years & $15 / 112(13.4)$ & I3// $35(9.6)$ & $1.4(0.7-3.2)$ & 0.342 & $0.7(0.3-1.6)$ & 0.401 \\
\hline Smoking $>5$ pack-years & $20 / 185$ (10.8) & $17 / 152(11.2)$ & $0.9(0.5-1.9)$ & 0.913 & $0.8(0.4-1.5)$ & 0.400 \\
\hline
\end{tabular}

Notes: Data are expressed as $\mathrm{n}(\%)$, with adjusted relative risk ratios for age, sex, and smoking status. *Significant difference.

Abbreviation: $\mathrm{Cl}$, confidence interval; COPD, chronic obstructive pulmonary disease.

because of low awareness of the disease, underdiagnosis, variability within age groups, and discrepancies in study methodologies..$^{14,15}$ Our findings have demonstrated the benefit of spirometric screening of COPD ${ }^{16}$ using the post-BD fixed ratio of $\mathrm{FEV}_{1} / \mathrm{FVC}<0.7$ as a discriminating criterion. The COPD prevalence in people aged more than 40 years were $3.7 \%$ and $6.8 \%$, respectively, in urban and rural communities, which is similar to previously reported findings from throughout $\mathrm{Asia}^{4,17}$ Our study prevalence was also lower than that from European countries using the same criteria, as has been reported elsewhere. ${ }^{18-21}$ Smoking has been identified as the major cause of COPD..$^{13}$ The prevalence of COPD in general, and particularly in females in the rural group tended to be higher than that in the urban group and was expected because historically, as previously reported, about half $(51.5 \%)$ of females living in rural communities in Thailand are smokers. ${ }^{22}$ However, after adjustment for confounding factors (age, sex, and smoking status), no significant differences were demonstrated. Further, $60.1 \%$ of rural patients in this study were underweight (BMI $<18.5 \mathrm{~kg} / \mathrm{m}^{2}$ ), and this is similar to results reported in our previous study. ${ }^{5}$ The rural and urban groups had equally low exposure to biomass fuel smoke (41.0 \pm 12.4 vs $31.7 \pm 8.8$ hour-years, respectively) $(P=0.649)$. A previous study revealed that the risk of chronic bronchitis increased with exposure to more than 100 houryears. ${ }^{9}$ All COPD subjects in the rural group were chronic smokers with no other known risk factors for airflow obstruction, whereas four $(19 \%)$ subjects in the urban group were nonsmokers. The four nonsmoking-related COPD subjects in the urban group were further investigated at the hospital and diagnosed as asthmatics with fixed airflow obstruction (two), bronchiectasis (one), and post-pulmonary tuberculous bronchiectasis (one) by pulmonologists. The majority of the COPD subjects in this study (28/41 [68.3\%]) were more than 60 years, and their prevalence $(13.4 \%$ and $9.6 \%$ in the rural and urban groups, respectively) was much higher than the prevalence of all population. These findings were similar to those of previous epidemiological studies, where the proportion of COPD sufferers showed an incremental increase in prevalence with increasing age and reached a peak in those over 60 years. ${ }^{16-20} \mathrm{~A}$ higher prevalence of COPD was also shown to be associated with sex (male), age (older), and smoking pack-years.

Only $12.2 \%$ of the COPD subjects in the two communities (14.3\% [urban] and $20.0 \%$ [rural]) were classified as mild (GOLD I). These rates are contrary to the findings of a large epidemiological study from Spain, in which $84.4 \%$ of the cases identified had mild disease. ${ }^{18}$ Although the pulmonary function between the two COPD groups were comparable, mild to moderate COPD (GOLD I and II) severity was mostly found in the urban group (66.7\%), whereas $65 \%$ of COPD subjects in the rural group were at severe to very severe stages (GOLD III and IV).

The rates of previously underdiagnosed COPD in both groups were equally high ( $76.2 \%$ [urban] and $80.0 \%$ [rural], respectively) and were similar to the rates reported in developed countries. ${ }^{18,21}$ No subjects diagnosed as COPD from either group in this study had ever been evaluated by spirometry, with the COPD diagnosis being made by presumptive diagnosis based on signs and symptoms. The underdiagnosis of this disease in real-world practices worldwide could be due to the cryptic nature of the disease and the underuse of spirometry. Because of underdiagnosis in most of the COPD subjects, standard pharmacological treatment and exercise training programs, as recommended by GOLD guidelines, were inaccessible to the majority. ${ }^{13}$ Improvements in diagnosis and the treatment of COPD, as well as in awareness of COPD risks, should be raised in Thailand. Treatment and prevention programs, in both urban and rural communities, should be implemented to reduce the prevalence, morbidity, and mortality associated with COPD.

The strengths of this study were firstly, the inclusion of chest radiographs in the preferential diagnosis of COPD, which excluded other obstructive pulmonary diseases (eg, pulmonary tuberculosis and chronic destroyed lung), 
Table 3 Characteristics of COPD between the urban and rural communities

\begin{tabular}{|c|c|c|c|}
\hline Characteristics & Rural $(n=20)$ & Urban $(n=2 I)$ & $P$-value \\
\hline Male sex & $14(70.0)$ & $18(85.7)$ & 0.224 \\
\hline Age (years) & $66.5 \pm 8.9$ & $61.1 \pm 11.1$ & 0.094 \\
\hline Age $>60$ years & $15(75.0)$ & $13(61.9)$ & 0.113 \\
\hline BMI $\left(\mathrm{kg} / \mathrm{m}^{2}\right)$ & $18.6 \pm 3.6$ & $22.8 \pm 4.3$ & 0.002 \\
\hline Occupation & & & 0.002 \\
\hline Laborer & $4(20.0)$ & II (52.4) & \\
\hline Farmer & $10(50.0)$ & $0(0.0)$ & \\
\hline Self-employed & $4(20.0)$ & $5(23.8)$ & \\
\hline Officer & $2(10.0)$ & $5(23.8)$ & \\
\hline Level of education & & & 0.002 \\
\hline Primary & $16(80.0)$ & $5(23.8)$ & \\
\hline Secondary & $4(20.0)$ & $9(42.9)$ & \\
\hline College & $0(0.0)$ & $6(28.6)$ & \\
\hline University & $0(0.0)$ & I (4.8) & \\
\hline Level of economic status (Baht/year) & & & 0.033 \\
\hline Low $(\leq 70,000)$ & $14(70.0)$ & $17(81.0)$ & \\
\hline Moderate $(70,00 \mathrm{I}-195,749)$ & $6(30.0)$ & I (4.8) & \\
\hline High $(>195,749)$ & $0(0.0)$ & $3(14.2)$ & \\
\hline Smoking status & & & 0.053 \\
\hline Nonsmoker & $0(0.0)$ & $4(19.0)$ & \\
\hline Smoker & $20(100.0)$ & $17(8 \mid .0)$ & \\
\hline Current smoker & $20(100.0)$ & $17(100.0)$ & \\
\hline Ex-smoker & $0(0.0)$ & $0(0.0)$ & \\
\hline Smoking (pack-years) & $35.7 \pm 27.2$ & $23.9 \pm 16.7$ & 0.056 \\
\hline Smoker $>5$ pack-years & $20(100.0)$ & $17(8 \mid .0)$ & 0.053 \\
\hline Duration of smoking (years) & $42.2 \pm 13.5$ & $30.3 \pm 15.5$ & 0.015 \\
\hline Biomass smoke status & & & 0.800 \\
\hline No exposure to biomass smoke & $10(50.0)$ & $12(57.1)$ & \\
\hline Exposure to biomass smoke level & $10(50.0)$ & $9(42.9)$ & \\
\hline$<100$ hour-years & $7(70.0)$ & $8(88.9)$ & 0.313 \\
\hline $100-200$ hour-years & $3(30.0)$ & I (II.I) & \\
\hline$>200$ hour-years & $0(0.0)$ & $0(0.0)$ & \\
\hline Duration of exposure (hour-years) & $42.3 \pm 35.0$ & $34.3 \pm 36.2$ & 0.630 \\
\hline$\%$ predicted FVC & $72.9 \pm 4.9$ & $73.4 \pm 17.3$ & 0.367 \\
\hline $\mathrm{FEV}_{1}(\mathrm{~L})$ & $1.16 \pm 0.62$ & $1.49 \pm 0.62$ & 0.064 \\
\hline$\%$ predicted $\mathrm{FEV}_{1}$ & $48.2 \pm 18.6$ & $58.6 \pm 17.5$ & 0.068 \\
\hline $\mathrm{FEV}_{1} / \mathrm{FVC}(\%)$ & $58.8 \pm 7.7$ & $63.1 \pm 6.3$ & 0.068 \\
\hline GOLD classification & & & 0.146 \\
\hline 1 & $2(20.0)$ & $3(14.3)$ & \\
\hline II & $5(25.0)$ & II (52.4) & \\
\hline III & $8(40.0)$ & $6(28.6)$ & \\
\hline IV & $5(25.0)$ & I (4.7) & \\
\hline Chest radiograph & & & 0.186 \\
\hline Normal & $3(15.0)$ & $2(9.5)$ & \\
\hline Compatible with COPD & $15(75.0)$ & $15(7 \mid .4)$ & \\
\hline Perihilar calcific spot & $0(0.0)$ & $3(14.3)$ & \\
\hline Likely tuberculosis & $0(0.0)$ & I (4.8) & \\
\hline Other & $2(10.0)$ & $0(0.0)$ & \\
\hline Previous spirometry & $0(0.0)$ & $0(0.0)$ & - \\
\hline Previous physician-diagnosed COPD & $6(20.0)$ & $5(23.8)$ & 0.655 \\
\hline Previous physician-treated COPD & $3(15.0)$ & $4(19.1)$ & 0.731 \\
\hline Previous exercise training program & $0(0.0)$ & $0(0.0)$ & - \\
\hline
\end{tabular}

Note: Data are expressed as $\mathrm{n}(\%)$ or mean \pm SD.

Abbreviations: BMI, body mass index; FEV , forced expiratory volume in I second; FVC, forced vital capacity; GOLD, Global Initiative for Chronic Obstructive Lung Disease; SD, standard deviation; COPD, chronic obstructive pulmonary disease. 
as well as the inclusion of post-BD spirometry diagnosis, as recommended by GOLD guidelines. ${ }^{13,23}$ Use of post- rather than pre-BD data alone can lower the estimated prevalence of COPD by $30 \%-50 \%{ }^{23-26}$ Secondly, we used the same instrument and the same qualified technician to evaluate patients in both groups, using methods that have been adopted as standard for comparing COPD prevalence across the globe.

The study had some limitations. Firstly, the difference in prevalence based on sex and region was altered by confounding factors, such as socioeconomic status, occupation, and education level, which were not addressed. Secondly, the numbers of COPD subjects from both groups were too small to assess the differences between them, if one existed. Thirdly, a selection bias was possible. This might be a confounder because comorbidities are commonly reported with COPD. ${ }^{27}$ Although the reasons for subject nonparticipation were not fully evaluated, a self-selection bias could lead to over- or underestimation of COPD prevalence. The lack of participation was most likely due to transportation issues for rural people. Fourthly, our findings were based on data from a single province only and might not be reliably generalized to other regions of Thailand. Moreover, the subjects in both groups lived in communities with convenient transportation therefore, the data might not be representative of COPD subjects living in wilderness communities.

\section{Conclusion}

The prevalence of COPD in general, particularly in females, tended to be higher in the rural community with a higher level of disease severity. However, both rural and urban groups were equally underdiagnosed and undertreated.

\section{Acknowledgments}

The authors wish to thank the subjects who kindly took part in this study, and to acknowledge the staff members of the Division of Pulmonary, Critical Care and Allergy, Department of Internal Medicine, Faculty of Medicine, Chiang Mai University, for their contribution to this trial.

\section{Author contributions}

CP developed the study design and carried out the acquisition and interpretation of data, the statistical analysis, manuscript preparation, and critical revision of intellectual content. The other authors contributed to the acquisition and interpretation of data, revised the article for important intellectual contents, and gave final approval of the version to be published.

\section{Disclosure}

The authors report no conflicts of interest in this work.

\section{References}

1. Lozano R, Naghavi M, Foreman K, et al. Global and regional mortality from 235 causes of death for 20 age groups in 1990 and 2010: a systematic analysis for the Global Burden of Disease Study 2010. Lancet. 2012;380(9859):2095-2128.

2. Mathers CD, Roncar D. Projections of global mortality and burden of disease from 2002 to 2030. PLoS Med. 2006;3(11):e442.

3. Halbert RJ, Natoli JL, Gano A, Badamgarav E, Buist AS, Mannino DM. Global burden of COPD: systematic review and meta-analysis. Eur Respir J. 2006;28(3):523-532.

4. Regional COPD Working Group. COPD prevalence in 12 Asia-Pacific countries and regions: projections based on the COPD prevalence estimation model. Respirology. 2003;8(2):192-198.

5. Pothirat C, Phetsuk N, Deesomchok A, et al. Clinical characteristics, management in real world practice and long-term survival among COPD patients of Northern Thailand COPD club members. J Med Assoc Thai. 2007;90(4):653-662.

6. Cochran WG. Sampling Techniques. 3rd ed. New York, NY: John Wiley and Sons Inc; 1977.

7. Burney PG, Luczynska C, Chinn S, Jarvis D. The European Community Respiratory Health Survey. Eur Respir J. 1994;7(5):954-960.

8. Li L, Borland R, Yong HH, et al. Predictors of smoking cessation among adult smokers in Malaysia and Thailand: findings from the International Tobacco Control Southeast Asia Survey. Nicotine Tob Res. 2010; 12 Suppl:S34-S44.

9. Pérez-Padilla R, Regalado J, Vedal S, et al. Exposure to biomass smoke and chronic airway disease in Mexican women. A case-control study. Am J Respir Crit Care Med. 1996;154(3 Pt 1):701-706.

10. Miller MR, Hankinson J, Brusasco V, et al; ATS/ERS Task Force. Standardisation of spirometry. Eur Respir J. 2005;26(2):319-338.

11. Hankinson JL, Odencrantz JR, Fedan KB. Spirometric reference values from a sample of the general U.S. population. Am J Respir Crit Care Med. 1999;159(1):179-187.

12. Hankinson JL, Kawut SM, Shahar E, Smith LJ, Stukovsky KH, Barr RG. Performance of American Thoracic Society-recommended spirometry reference values in a multiethnic sample of adults: the multi-ethnic study of atherosclerosis (MESA) lung study. Chest. 2010;137(1):138-145.

13. Rabe KF, Hurd S, Anzueto A, et al; Global Initiative for Chronic Obstructive Lung Disease. Global strategy for the diagnosis, management, and prevention of chronic obstructive pulmonary disease: GOLD executive summary. Am J Respir Crit Care Med. 2007;176(6):532-555.

14. Celli BR. The light at the end of the tunnel: is COPD prevalence changing? Eur Respir J. 2010;36(4):718-719.

15. Cerveri I, De Marco R. What makes large epidemiological studies comparable? Eur Respir J. 2010;36(4):720-721.

16. Soriano JB, Zielinski J, Price D. Screening for and early detection of chronic obstructive pulmonary disease. Lancet. 2009;374(9691): 721-732.

17. Kim SJ, Suk MH, Choi HM, et al. The local prevalence of COPD by postbronchodilator GOLD criteria in Korea. Int J Tuberc Lung Dis. 2006; 10(12):1393-1398.

18. Soriano JB, Ancochea J, Miravitlles M, et al. Recent trends in COPD prevalence in Spain: a repeated cross-sectional survey 1997-2007. Eur Respir J. 2010;36(4):758-765.

19. Caballero A, Torres-Duque CA, Jaramillo C, et al. Prevalence of COPD in five Colombian cities situated at low, medium, and high altitude (PREPOCOL study). Chest. 2008;133(2):343-349.

20. Bridevaux PO, Probst-Hensch NM, Schindler C, et al. Prevalence of airflow obstruction in smokers and never-smokers in Switzerland. Eur Respir J. 2010;36(6):1259-1269.

21. Peña VS, Miravitlles M, Gabriel R, et al. Geographic variations in prevalence and underdiagnosis of COPD: results of the IBERPOC multicentre epidemiological study. Chest. 2000;118(4):981-989. 
22. Janes C, Stall R, Gifford SM, editors. Anthropology and Epidemiology: Interdisciplinary Approaches to the Study of Health and Disease. Dordrecht: D. Reidel Publishing Company; 1986.

23. Sterk PJ. Let's not forget: the GOLD criteria for COPD are based on post-bronchodilator FEV1. Eur Respir J. 2004;23(4):497-498.

24. Johannessen A, Omenaas ER, Bakke PS, Gulsvik A. Implications of reversibility testing on prevalence and risk factors for chronic obstructive pulmonary disease: a community study. Thorax. 2005;60(10): 842-847.
25. Shirtcliffe P, Weatherall M, Marsh S, et al. COPD prevalence in a random population survey: a matter of definition. Eur Respir J. 2007; 30(2):232-239.

26. Pellegrino R, Viegi G, Brusasco V, et al. Interpretative strategies for lung function tests. Eur Respir J. 2005;26(5):948-968.

27. Chatila WM, Thomashow BM, Minai OA, Criner GJ, Make BJ. Comorbidities in chronic obstructive pulmonary disease. Proc Am Thorac Soc. 2008;5(4):549-555.

\section{Publish your work in this journal}

The International Journal of COPD is an international, peer-reviewed journal of therapeutics and pharmacology focusing on concise rapid reporting of clinical studies and reviews in COPD. Special focus is given to the pathophysiological processes underlying the disease, intervention programs, patient focused education, and self management protocols.

\section{Dovepress}

This journal is indexed on PubMed Central, MedLine and CAS. The manuscript management system is completely online and includes a very quick and fair peer-review system, which is all easy to use. Visit $\mathrm{http}: / / \mathrm{www}$.dovepress.com/testimonials.php to read real quotes from published authors. 